УдК 004.72+004.032.6+378

( О. Г. Хамула, к.т.н., доцент, А. Д. Конюхов, аспірант, Українська академія друкарства, Львів, Україна

\title{
РОЗРОБКА МОДЕЛІ ФАКТОРІВ ВПЛИВУ НА ЕКСПЛУАТАЦІЙНІ ПОКАЗНИКИ ПЛАСТИКОВИХ КАРТОК
}

У статті розглянуто проблеми, які виникають при експлуатації пластикових карток та шляхи їх вирішення. Запропоновано для вирішення поставлених завдань використати методи системного і матричного аналізу, теорії графів - для виділення та формалізації подання зв'язків між факторами впливу на експлуатаційні властивості пластикових карток. За допомогою проведеного аналізу факторів, які впливають на експлуатаційні показники пластикових карток, дало можливість побудувати структуровану модель ієрархії з виявленням пріоритетності їх впливу на процес виготовлення. Отримана модель показує, що найважливішим фактором $\epsilon$ матеріали, що використовується для виготовлення пластикових карток. Вид матеріалу впливає на процеси виготовлення та обробки, що забезпечує якість та довговічність пластикових карток. Не менш важливими є: способи друку та обробки пластикових карток, адже від них залежить весь подальший технологічний процес.

Ключові слова: пластикові картки; фактори впливу; теорія графів; матричний аналіз; бінарна матриця; модель ієрархії; експлуатація.

\section{Постановка проблеми}

За останні роки пластикові картки, що стали стандартним атрибутом життя у економічно розвинутих країнах, усе більше поширюються у нашій країні. Вони впевнено увійшли у наше життя. Завдяки надійності та зручності у використанні пластикові картки застосовуються у багатьох сферах комерційної діяльності.

Пластикові картки як новий вид продукції вимагає зіставлення технічних можливостей процесів і обладнання, добору матеріалів, встановлення саме тих параметрів технологічних режимів, що здатні забезпечити унормовані показники якості виробів. Друкарський процес на полімерних плівках i пластиках - непросте завдання, оскільки адгезійні властивості фарби і змочуваність пластику є низькими [1-3].

Тому дослідження технологічних процесів виробництва пластикових карток з метою їх удосконалення, а також визначення

(C) $2016 p$. 
факторів впливу на експлуатаційні показники пластикових карток $€$ актуальною темою для дослідження.

\section{Аналіз попередніх досліджень}

Теоретичні, методичні, економіко-організаційні питання формування ринку сучасних карткових платіжних інструментів стали провідними темами дослідження відомих зарубіжних та вітчизняних економістів, зокрема: С. Бочкарьова, А. Єпіфанова, Р. Капралова, В. Кравця, Н. Лапко, В. Міщенка, О. Марченка, О. Мозгового, А. Мороза, С. Науменкової, Ю. Пахомова, М. Савлука, А. Савченка, І. Сало, В. Стельмаха, В. Страхарчука, В. Торхова, І. Демчова, В. Харченка, С. Цокола, Я. Чайковського, В. Ющенка та ін.

Розробленню засобів систем управління процесом друкування та оцінці якості відбитків присвячені роботи: Дурняка Б. В.,
Гавенко С. Ф., Лазаренка Е. Т., Сікори Л. С., Луцківа М. М., Сеньківського В. М., Шовгенюка М. В., Тимченка О. В. та ін. [4].

Проте проведений аналіз літературних джерел та патентної інформації показав, що використання методу системного і матричного аналізу, теорії графів для виділення та формалізації зв'язків між факторами впливу на експлуатаційні властивості пластикових карток на сьогодні ще недостатньо вивчені.

\section{Мета роботи}

Розглянути та дослідити фактори, які впливають на експлуатаційні показники пластикових карток. Побудувати математичну модель ієрархії факторів впливу на експлуатаційні показники пластикових карток і в результаті обчислень отримати ієрархічно структуровану модель, що імітує пріоритетність впливу вибраних факторів на процес проектування пластикових карток.

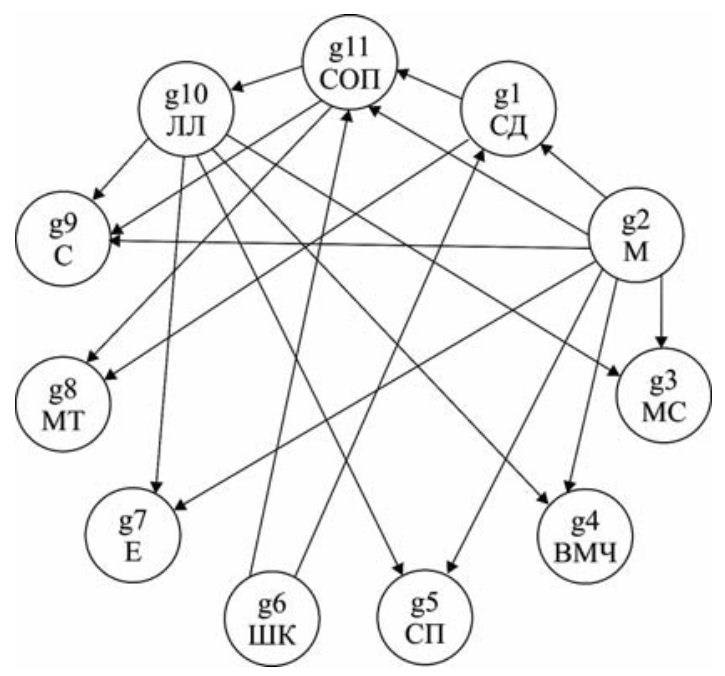

Рис. 1. Граф зв'язків між факторами впливу на експлуатаційні показники пластикових карток 


\section{Результати проведених досліджень}

Серед факторів, які впливають на експлуатаційні показники пластикових карток, в процесі опитування респондентів було виділено:

g1. Спосіб друку (СД);

g2. Матеріали для виготовлення (М);

g3. Магнітна смуга (МC);

g4. Встановлення мікрочіпа (BM4);

g5. Скретч-покриття (СП);

g6. Штрих-код (ШК);

g7. Ембосування (Е);

g8. Мікротекст (МT);

g9. Смуга (панель) для підпиcy $(\mathrm{C})$;

g10. Лакування, ламінування (ЛЛ);

g11. Способи обробки поверхні пластикових матеріалів (СОП).
Сукупність розглянутих факторів складає множину $\mathrm{G}=\left\{\mathrm{g}_{1}, \mathrm{~g}_{2}\right.$, $\left.\ldots, g_{n}\right\}, ~ з$ якої можна визначити підмножину $\mathrm{G} 1 \in \mathrm{G}$ найбільш суттєвих факторів. Доповнимо математичне позначення видання мнемонічною назвою.

Підмножину факторів G1 та можливий взаємовплив між ними відобразимо у вигляді орієнтовного графу (рис. 1.).

На основі поданого графу будуємо бінарну матрицю залежності В з використанням залежності [5]:

$b_{i j}=\left\{\begin{array}{l}0, \text { якщо фактор i не залежить від фактора j } \\ 1, \text { якщо фактор і залежить від фактора j }\end{array}\right.$

Для кращого відображення матрицю G помістимо в табл. 1, додавши до неї інформаційний рядок і стовпець 3 мнемонічними назвами факторів.

Бінарна матриця залежності

Таблиця 1

\begin{tabular}{|c|c|c|c|c|c|c|c|c|c|c|c|c|}
\hline & & 1 & 2 & 3 & 4 & 5 & 6 & 7 & 8 & 9 & 10 & 11 \\
\hline & & СД & М & МС & ВМЧ & СП & ШК & Е & МТ & С & лЛ & СОП \\
\hline 1 & СД & 0 & 0 & 0 & 0 & 0 & 0 & 0 & 1 & 0 & 0 & 1 \\
\hline 2 & М & 1 & 0 & 1 & 1 & 1 & 0 & 1 & 0 & 1 & 0 & 1 \\
\hline 3 & МС & 0 & 0 & 0 & 0 & 0 & 0 & 0 & 0 & 0 & 0 & 0 \\
\hline 4 & ВМЧ & 0 & 0 & 0 & 0 & 0 & 0 & 0 & 0 & 0 & 0 & 0 \\
\hline 5 & СП & 0 & 0 & 0 & 0 & 0 & 0 & 0 & 0 & 0 & 0 & 0 \\
\hline 6 & ШК & 1 & 0 & 0 & 0 & 0 & 0 & 0 & 0 & 0 & 0 & 1 \\
\hline 7 & Е & 0 & 0 & 0 & 0 & 0 & 0 & 0 & 0 & 0 & 0 & 0 \\
\hline 8 & МТ & 0 & 0 & 0 & 0 & 0 & 0 & 0 & 0 & 0 & 0 & 0 \\
\hline 9 & С & 0 & 0 & 0 & 0 & 0 & 0 & 0 & 0 & 0 & 0 & 0 \\
\hline 10 & ЛЛ & 0 & 0 & 1 & 1 & 1 & 0 & 1 & 0 & 1 & 0 & 0 \\
\hline 11 & СОП & 0 & 0 & 0 & 0 & 0 & 0 & 0 & 1 & 1 & 1 & 0 \\
\hline
\end{tabular}


На основі графу побудовано матрицю досяжності. Ї̈̈ побудова зводиться до заповнення табл. 2, бінарні елементи якої визначаються за логічним правилом:

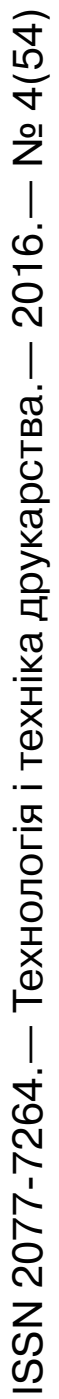
них вище дій дае перший рівен

ієрархії факторів. Для визначення вказаного рівня на основі попередньої матриці та з використанням описаних залежностей будуємо табл. 3.

3 таблиці видно, що рівність $\mathrm{A}\left(\mathrm{g}_{\mathrm{i}}\right)=\mathrm{R}\left(\mathrm{g}_{\mathrm{i}}\right) \cap \mathrm{A}\left(\mathrm{g}_{\mathrm{i}}\right)$ виконується для елементів з номером 2 і 6. Аналогічно, за описаним методом одержуємо всі наступні рівні ієрархії.

Таким чином, у результаті виконання дій над елементами початкового графу (рис. 1) одержано ієрархічно структуровану модель (рис. 2), що імітує пріоритетність впливу вибраних факторів на експлуатаційні показники пластикових карток.

\section{Висновки}

В процесі проведеного дослідження було створено модель

Таблиця 2

Матриця досяжності

\begin{tabular}{|c|c|c|c|c|c|c|c|c|c|c|c|c|}
\hline & & 1 & 2 & 3 & 4 & 5 & 6 & 7 & 8 & 9 & 10 & 11 \\
\hline & & СД & М & МС & ВМЧ & СП & ШК & Е & МТ & С & лЛ & СОП \\
\hline 1 & СД & 1 & 0 & 1 & 1 & 1 & 0 & 1 & 1 & 1 & 1 & 1 \\
\hline 2 & М & 1 & 1 & 1 & 1 & 1 & 0 & 1 & 1 & 1 & 1 & 1 \\
\hline 3 & МС & 0 & 0 & 1 & 0 & 0 & 0 & 0 & 0 & 0 & 0 & 0 \\
\hline 4 & ВМЧ & 0 & 0 & 0 & 1 & 0 & 0 & 0 & 0 & 0 & 0 & 0 \\
\hline 5 & СП & 0 & 0 & 0 & 0 & 1 & 0 & 0 & 0 & 0 & 0 & 0 \\
\hline 6 & ШК & 1 & 0 & 1 & 1 & 1 & 1 & 1 & 1 & 1 & 1 & 1 \\
\hline 7 & Е & 0 & 0 & 0 & 0 & 0 & 0 & 1 & 0 & 0 & 0 & 0 \\
\hline 8 & МТ & 0 & 0 & 0 & 0 & 0 & 0 & 0 & 1 & 0 & 0 & 0 \\
\hline 9 & С & 0 & 0 & 0 & 0 & 0 & 0 & 0 & 0 & 1 & 0 & 0 \\
\hline 10 & ЛЛ & 0 & 0 & 1 & 1 & 1 & 0 & 1 & 0 & 1 & 1 & 0 \\
\hline 11 & СОП & 0 & 0 & 1 & 1 & 1 & 0 & 1 & 1 & 1 & 1 & 1 \\
\hline
\end{tabular}


Таблиця 3

Визначення першого рівня ієрархії факторів

\begin{tabular}{|c|c|c|c|}
\hline $\mathrm{g}_{\mathrm{i}}$ & $\mathrm{R}\left(\mathrm{g}_{\mathrm{i}}\right)$ & $\mathrm{A}\left(\mathrm{g}_{\mathrm{i}}\right)$ & $\mathrm{R}\left(\mathrm{g}_{\mathrm{i}}\right) \cap \mathrm{A}\left(\mathrm{g}_{\mathrm{i}}\right)$ \\
\hline 1 & $1,3,4,5,7,8,9,10,11$ & $1,2,6$ & 1 \\
\hline 2 & $1,2,3,4,5,7,8,9,10,11$ & 2 & 3 \\
\hline 3 & 3 & $1,2,3,6,10,11$ & 4 \\
\hline 4 & 4 & $1,2,4,6,10,11$ & 5 \\
\hline 5 & 5 & $1,2,5,6,10,11$ & 6 \\
\hline 6 & $1,3,4,5,6,7,8,9,10,11$ & 6 & 7 \\
\hline 7 & 7 & $1,2,6,7,10,11$ & 9 \\
\hline 8 & 3 & $1,2,6,8,11$ & 10 \\
\hline 9 & 9 & $1,2,6,9,10,11$ & 11 \\
\hline 10 & $3,4,5,7,9,10$ & $1,2,6,10,11$ & 8 \\
\hline 11 & $3,4,5,7,8,9,10,11$ & $1,2,6,11$ & 2 \\
\hline
\end{tabular}

факторів впливу на експлуатаційні показники пластикових карток. Аналіз цих факторів дав можливість побудувати структуровану модель ієрархії з виявленням пріоритетності їх впливу на процес виготовлення. Отримана модель показує, що найважливішим фактором є матеріали для виготовлення пластикових карток. Вид матеріалу впливає на процеси виготовлення та обробки, що забезпечить якість та довговічність пластикових карток. Не менш важливими $€$ способи друку та способи обробки пластикових карток, адже від них залежить технологічний процес. На найнижчому рівні знаходяться елементи персоналізації та захисту пластикових карток.

Таблиця 4

Визначення останнього рівня ієрархії факторів

\begin{tabular}{|c|c|c|c|}
\hline $\mathrm{g}_{\mathrm{i}}$ & $\mathrm{R}\left(\mathrm{g}_{\mathrm{i}}\right)$ & $\mathrm{A}\left(\mathrm{g}_{\mathrm{i}}\right)$ & $\mathrm{R}\left(\mathrm{g}_{\mathrm{i}}\right) \cap \mathrm{A}\left(\mathrm{g}_{\mathrm{i}}\right)$ \\
\hline 3 & 3 & 3 & 3 \\
\hline 4 & 4 & 4 & 4 \\
\hline 5 & 5 & 5 & 5 \\
\hline 7 & 7 & 7 & 7 \\
\hline 9 & 9 & 9 & 9 \\
\hline
\end{tabular}




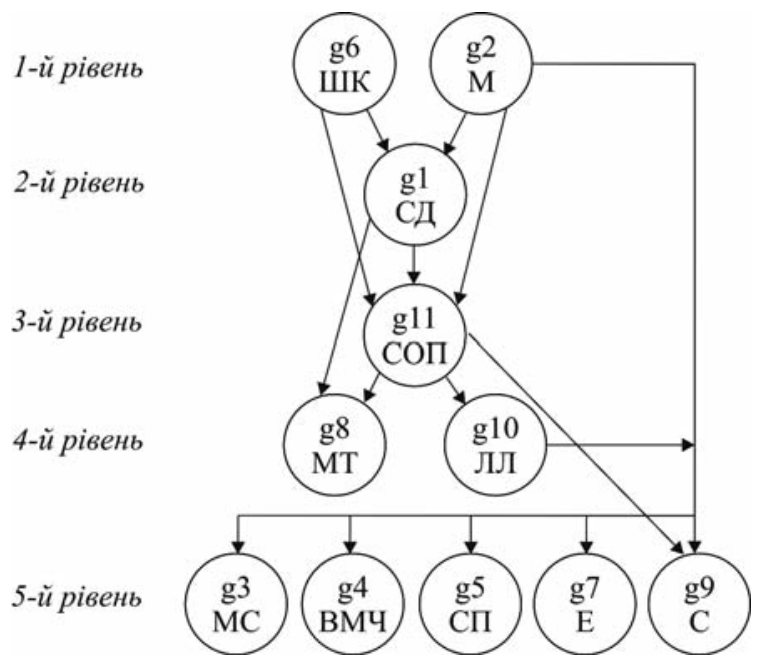

Рис. 2. Модель ієрархії факторів впливу на експлуатаційні показники пластикових карток

\section{Список використаної літератури}

1. Величко О. М. Пластикові картки : науково-технічні аспекти поліграфічного оформлення / О. Величко, І. Кириченко, В. Саражинська, І. Синяков [Текст] : монографія. - К. : ВПЦ «Київський університет», 2010. - 156 с.

2. Технології виготовлення пластикових карток : моногр., В. З. Маїк, Ю. М. Румянцев, І. І. Конюхова, М. Ф. Ясінський, Л. Я. Маїк. - Львів : УАД, 2015. - $144 \mathrm{c}$.

3. Григор'єв С. Ф. Методи захисту пластикових карток [Текст] / С. Ф. Григор'єв, В. А. Глива, А. Д. Давидюк [та ін.] // Ідентифікаційні картки та ідентифікація особи : зб. наук. праць. - К. : УкрIHTEI, 2000. - С. 8-14.

4. Сеньківський В. М. Модель ієрархії критеріїв якості книжкових видань / В. М. Сеньківський // Наукові записки УАД. - Львів, 2007. - Вип. 11. - С. 73-80.

5. Лямець В. І. Системний аналіз. Вступний курс / В. І. Лямець, А. Д. Тевяшев. - 2-е вид., переробл. та допов. - Харків : ХНУРЕ, 2004. - 448 с.

6. Сорока К. О. Основи теорії систем і системного аналізу / К. О. Сорока : навчальний посібник. - 2-е вид., переробл. та допов. - Харків, 2005.

\section{References}

1. Velychko, O. \& Kyrychenko, I. \& Sarazhynska, V. \& Syniakov, I. (2010). Plastykovi kartky: naukovo-tekhnichni aspekty polihrafichnoho oformlennia [Plastic cards: scientific and technical aspects of printing design]. Kyiv: VPTs 'Kyivskyi universytet' [in Ukrainian].

2. Maik, V. Z. \& Rumiantsev, lu. M. \& Koniukhova, I. I. \& Yasinskyi, M. F. \& Maik, L. la. (2015). Tekhnolohii vyhotovlennia plastykovykh kartok [Technologies of production of plastic cards]. Lviv: UAD [in Ukrainian]. 
3. Hryhor'iev, S. F. \& Hlyva, V. A. \& Davydiuk, A. D. [etc.] (2000). Metody zakhystu plastykovykh kartok [Methods of protection of plastic cards]. Journal of Identyfikatsiini kartky ta identyfikatsiia osoby. - Identification cards and personal identification, 8-14 [in Ukrainian].

4. Senkivskyi, V. M. (2007). Model iierarkhii kryteriiv yakosti knyzhkovykh vydan [The model of hierarchy of criteria for quality books]. Journal of Naukovi zapysky UAD. - Scientific notes of the UAP, 11, 73-80 [in Ukrainian].

5. Liamets, V. I. \& Teviashev, A. D. (2004). Systemnyi analiz. Vstupnyi kurs [System analysis. Introductory course]. Kharkiv: KhNURE [in Ukrainian].

6. Soroka, K. O. (2005). Osnovy teorii system i systemnoho analizu [Fundamentals of the theory of systems and system analysis]. Kharkiv [in Ukrainian].

В статье рассмотрены проблемы, возникающие при эксплуатации пластиковых карт и пути их решения. Предложено для решения поставленных задач, использовать методы системного и матричного анализа, теории графов - для вы-деления и формализации представления связей между факторами влияния на эксплуатационные свойства пластиковых карт. С помощью проведенного анализа факторов, влияющих на эксплуатационные показатели пластиковых карт, позволило построить структурированную модель иерархии с выявлением приоритетности их влияния на процесс изготовления. Полученная модель показывает, что важнейшим фактором являются материалы, что используются для изготовления пластиковых карт. Вид материала влияет на процессы изготовления и обработки, обеспечит качество

и долговечность пластиковых карт. Не менее важными являются: способы печати и способы обработки пластиковых карт, ведь от них зависит весь последующий технологический процесс.

Ключевые слова: пластиковые карточки; факторы влияния; теория графов; матричный анализ; бинарная матрица; модель иерархии; эксплуатация.

The article deals with the problems arising during the operation of plastic cards and their solutions. The methods of system and matrix analysis, graph theory are proposed to use to achieve the objectives - to highlight the presentation and formalization of relations between the factors of influence on the performance characteristics of plastic cards. The use of the analysis of factors influencing the operating performance of plastic cards, allowed to build a structured hierarchy model with the identification of priority of their impact on the manufacturing process. The resulting model shows that the most important factor is the materials that are used 
for the manufacture of plastic cards. Type of material influences the manufacturing and handling processes, and it ensures the quality and durability of plastic cards.

No less important are: printing methods and handling processes of plastic cards, because all subsequent processes depends on them.

Keywords: plastic cards; impact factors; graph theory; matrix analysis; binary matrix; model hierarchy; exploitation.

\author{
Рецензент - О. М. Величко, д.т.н., професор, \\ с.н.с., КПІ ім. Ігоря Сікорського
}

Надійшла до редакції 27.11.16 